\title{
Short chain lead (II) alkanoates as ionic liquids and glass formers: A d.s.c., X-ray diffraction and FTIR spectroscopy study
}

\author{
F.J. Martínez Casado ${ }^{\text {a }}$, A. Sánchez Arenas ${ }^{\text {b }}$, M.V. García Pérez ${ }^{\text {a }}$, M.I. Redondo Yélamos ${ }^{\text {a }}$, \\ S. López de Andrés ${ }^{\mathrm{c}}$, J.A.R. Cheda ${ }^{\mathrm{a}, *}$ \\ a Departamento de Química Física, Facultad de Ciencias Químicas, Universidad Complutense, 28040 Madrid, Spain \\ ${ }^{\mathrm{b}}$ Sección Departamental de Física Aplicada I, Facultad de Veterinaria, Spain \\ ${ }^{\mathrm{c}}$ Departamento de Cristalografía, Facultad de Ciencias Geológicas, Universidad Complutense, 28040 Madrid, Spain
}

Received 5 July 2006; received in revised form 18 July 2006; accepted 19 July 2006

Available online 11 August 2006

\begin{abstract}
Three members of the lead (II) $n$-alkanoates (from etanoate to $n$-butanoate) have been synthesized, purified and studied by d.s.c., Xray diffraction, and FTIR spectroscopy. Lead (II) acetate, propanoate, and butanoate present only a melting transition at $T=(452.6$, 398.2 , and 346.5) $\mathrm{K}$, with $\Delta_{\mathrm{f}} H=(16.0,13.1$, and 15.6$) \mathrm{kJ} \cdot \mathrm{mol}^{-1}$, and $\Delta_{\mathrm{f}} S=(35.3,32.8$, and 45.1$) \mathrm{J} \cdot \mathrm{mol}^{-1} \cdot \mathrm{K}^{-1}$, respectively. These temperature data correct to a great extent the historical values reported in the literature. These three members readily quench into a glass state. Their corresponding $T_{\mathrm{g}}$ values are $(314.4,289.0$, and 274.9$) \mathrm{K}$, respectively, measured by d.s.c. at a heating rate of $5 \mathrm{~K} \cdot \mathrm{min}^{-1}$.
\end{abstract}

Keywords: Lead (II) short alkanoates; Glass; Ionic liquid; d.s.c.; FTIR; XRD

\section{Introduction}

Lead (II) $n$-alkanoates series $\left(\mathrm{Pb}(\mathrm{Cn})_{2}\right.$, where $n$ is the total number of carbons of the alkanoate group, hereafter) have been largely studied by several authors [1-5]. The main feature of this series (for $n \geqslant 6$ ), is the presence of polymesomorphism: there is a first transition from a well organized crystal to a mesophase, characterized by a conformational disorder in the alkyl chain (called "condis" phase [6,7]), and followed by a fusion to a neat phase or "smectic A like", which goes into a stable isotropic liquid (ionic) at the "clearing" point. The thermal behaviour of all the members of the series above $n=6$ is reversible on heating and cooling the samples several times. Only small under cooling effects were observed, typical of the firstorder transitions.

\footnotetext{
* Corresponding author. Tel.: +34 91 3944306; fax: +91 3944135 . E-mail address: cheda@quim.ucm.es (J.A.R. Cheda).
}

Short members of the series were barely studied, but it is necessary to know their behaviour to understand better the whole lead (II) alkanoate series. In our knowledge, there is no literature information on the lead (II) $n$-pentanoate member. Its behaviour is under study and was found to be so complicated that a special attention has to be paid to this compound. The physical chemistry data found for the three short members, $\mathrm{Pb}(\mathrm{C} 2)_{2}, \mathrm{~Pb}(\mathrm{C} 3)_{2}$, and $\mathrm{Pb}(\mathrm{C} 4)_{2}$, are dated and taken on not well-identified samples. For instance, melting points reported for $\mathrm{Pb}(\mathrm{C} 2)_{2}$ and $\mathrm{Pb}(\mathrm{C} 4)_{2}$ in CRC Handbook of Chemistry and Physics (2005 edition) are $T=(553$ and 363$) \mathrm{K}$, respectively, which greatly differ from the values reported in this work, viz $T=(452.6$ and 346.5$) \mathrm{K}$, respectively. We attribute this lack of reliable data to the difficulties in the synthesis and purification of these compounds when following the usual methods described in the literature $[8,9]$. We used a new method of synthesis that allowed us to succeed in obtaining very pure samples (see section 2.1).

On the other hand, although the shortest chain members of this series do not behave as thermotropic liquid crystals 
(only members from $n=6$ to 12 present thermotropic liquid crystal behaviour $[5,10]$ ), they present a rather new interest as "Ionic Liquids" [11,12]. The compounds studied here melt at relative low temperatures in comparison with any other homologous series with other cations (e.g., sodium or potassium, earth alkaline, or thallium (I) $n$-alkanoates [10]). Actually, lead (II) butanoate has its melting point below $T=373 \mathrm{~K}$ (see section 3.1). So, it can be considered as an Ionic Liquid, according to the generally accepted IUPAC definition for these neoteric materials. This aspect makes them very interesting for the possibility of being used as a non-volatile ionic solvent ("designer solvent").

One interesting aspect of these short members is that, although they are not thermotropic mesogens, they may form lyotropic mesophases when mixed with another analogous salt with the same anion and different (size or charge) cation [13]. This ionic lyotropic mesophase combines both ionic liquid and liquid crystal properties (mainly the orientational order in a fluid phase), making them even much more interesting systems. Previous to the study of these binary phase diagrams is to know perfectly the thermal behaviour of the pure components.

Another interesting feature of metal alkanoates is the formation of the glass state. It has been well known for more than 30 years $[14,15]$ that metal acetate systems (acetate or their binary mixtures) have a strong tendency to form glasses.

All the compounds studied here readily quench into a glass state. Lead (II) acetate glass was already known [16]. What is new so far in our knowledge is that lead (II) propanoate and butanoate behave similarly to lead acetate.

\section{Experimental}

\subsection{Sample preparation}

In the case of the $\mathrm{Pb}(\mathrm{C} 2)_{2}$, a commercial lead(II) acetate trihydrated sample (Fluka, $>99.5 \%$ ) was first dehydrated by heating at $T=415 \mathrm{~K}$ under vacuum. It was recrystallized later in ethanol (Merck, $\geqslant 99.8$ ) several times and vacuum dried again.

On the other hand, $\mathrm{Pb}(\mathrm{C} 3)_{2}$ and $\mathrm{Pb}(\mathrm{C} 4)_{2}$, were prepared by reaction between the corresponding acid (propionic and butyric acids, both Fluka, $\geqslant 99.5$ ) and lead (II) oxide (Aldrich, $\geqslant 99.8$ ) in ethanol, being later recrystallized in ethanol and vacuum dried. Surprisingly, this is, to our knowledge, the first time that this method was used to synthesize these compounds.

The purity of all compounds was monitored by d.s.c., FTIR spectroscopy, and elemental analysis. The d.s.c. purity determinations, average of at least three measurements, were $99.55 \%, 99.73 \%$, and $99.63 \%$, for $\mathrm{Pb}(\mathrm{C} 2)_{2}, \mathrm{~Pb}(\mathrm{C} 3)_{2}$, and $\mathrm{Pb}(\mathrm{C} 4)_{2}$, respectively. A polarizing light microscope was used to identify the phases as solids, or liquids, or glasses.

\subsection{Differential scanning calorimetry}

A Seiko Instruments Inc. d.s.c., Model 22, in connection with the control unit SSC5100 d.s.c. was used to register all the thermograms. Tightly sealed aluminium volatile pans, with samples weighing about $(10 \pm 0.001) \mathrm{mg}$, were scanned at heating rates of $5 \mathrm{~K} \cdot \mathrm{min}^{-1}$ in air. The instrument was calibrated for temperature using standard In and Sn samples, supplied by Mettler (mass fraction purity $>0.99999$ and $>0.999$, respectively), and standard benzoic acid (mass fraction purity $>0.9997$ ), supplied by the former NBS (lot 39i). Calibration in energy (enthalpy) was done by means of the same standard In and Sn samples, already described.

\subsection{Optical microscopy}

To identify the nature of the phases (solid, liquid crystal, glass, or liquid), a Carl Zeiss-Jena polarizing optical microscope, model Zeiss Jenalab pol-30-G0527, equipped with a LINKAM hot stage, model THMS600, connected to a LINKAM programmable temperature-controller, model TMS94, was used.

\section{4. $X$-ray diffraction}

Samples were measured at room temperature in reflection mode in a Panalytical X'Pert PRO Alphal diffractometer equipped with a curved Ge111 primary beam monochromator and a fast detector X'Celerator $\left(\mathrm{Cu} \mathrm{K} \alpha_{1}\right.$ radiation, $45 \mathrm{kV}, 40 \mathrm{~mA}$ ). The measurement range of $2 \theta$ was from $3^{\circ}$ to $70^{\circ}$, and step size $0.0167^{\circ}$.

\subsection{FTIR spectroscopy}

Infrared spectra of $\mathrm{Pb}$ (II) alkanoates in $\mathrm{KBr}$ pellets and as powder between two $\mathrm{KBr}$ crystals were recorded using a Nicolet Magna 750 FTIR spectrometer at a resolution of $2 \mathrm{~cm}^{-1}$ in the mid infrared. No significant differences between spectra of samples prepared as pellets or as powder were found. A commercial variable temperature cell, SPECAC VTL-2, adapted for solid samples was employed to obtain IR spectra at different temperatures.

\section{Results and discussion}

\subsection{Differential scanning calorimetry}

In figures 1 to 4 , thermographs of specified compounds are shown. All the plots of figures 1, 2, and 4 have the same heat flow units (ordinate), and were displaced one to another to make their comparison clearer. The heating rate for all the d.s.c. thermograms was $5 \mathrm{~K} \cdot \mathrm{min}^{-1}$. The three members studied were explored in the temperature range of $173 \mathrm{~K}$ to $600 \mathrm{~K}$. However, thermal effects were found only in the ranges $T=(253$ to 523,253 to 423 , and 243 to 383$) \mathrm{K}$ for $\mathrm{Pb}(\mathrm{C} 2)_{2}, \mathrm{~Pb}(\mathrm{C} 3)_{2}$, and $\mathrm{Pb}(\mathrm{C} 4)_{2}$, respectively. 


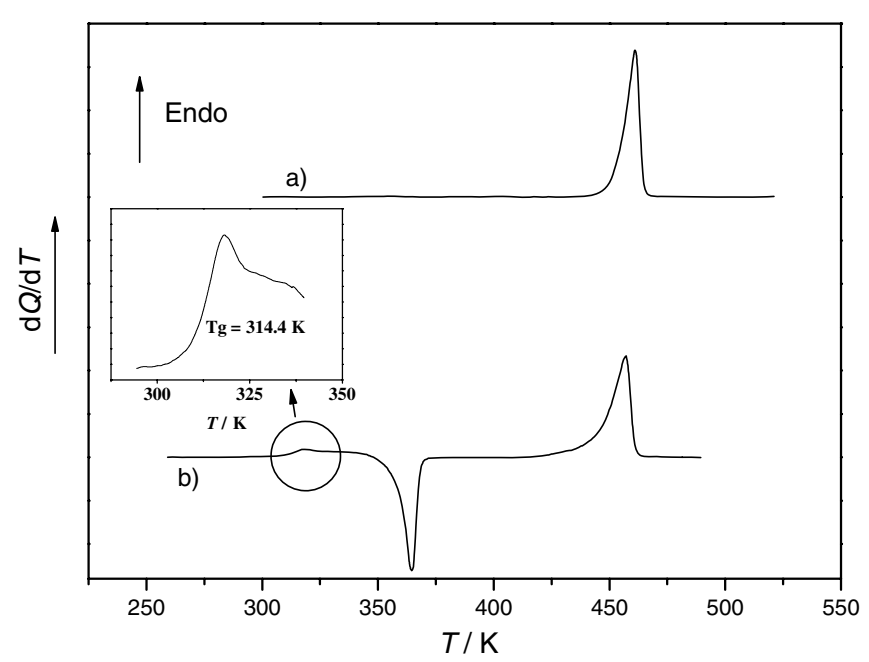

FIGURE 1. $\mathrm{Pb}(\mathrm{C} 2)_{2}$ d.s.c. thermograms: (a) first and (b) second and following heatings.

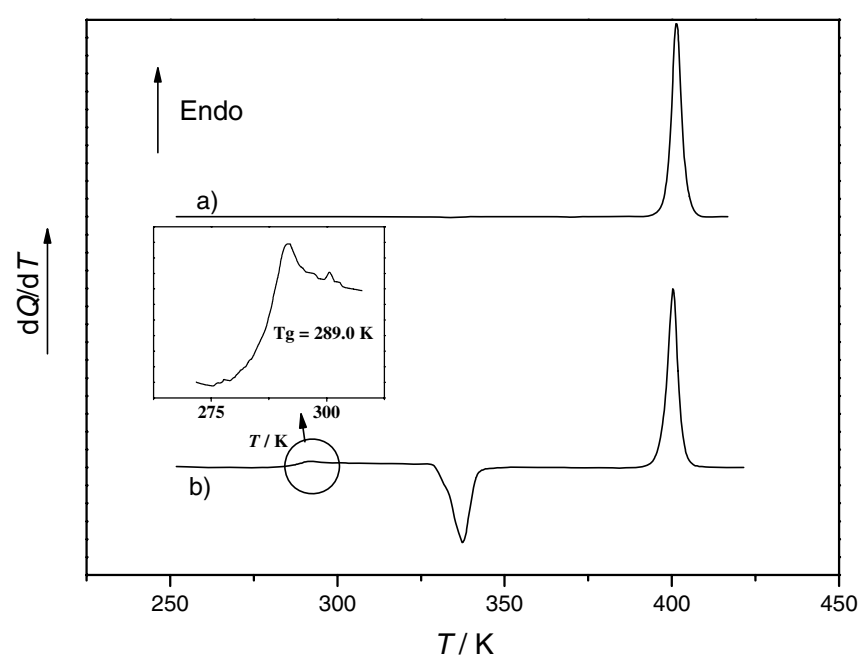

FIGURE 2. $\mathrm{Pb}(\mathrm{C} 3)_{2}$ d.s.c. thermograms: (a) first and (b) second and following heatings.

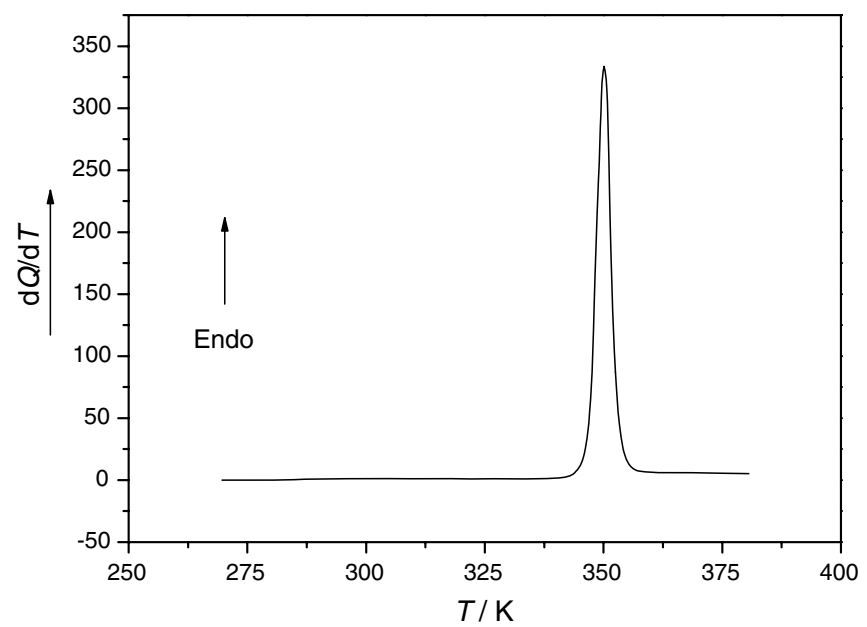

FIGURE 3. $\mathrm{Pb}(\mathrm{C} 4)_{2}$ d.s.c. thermogram, first heating.

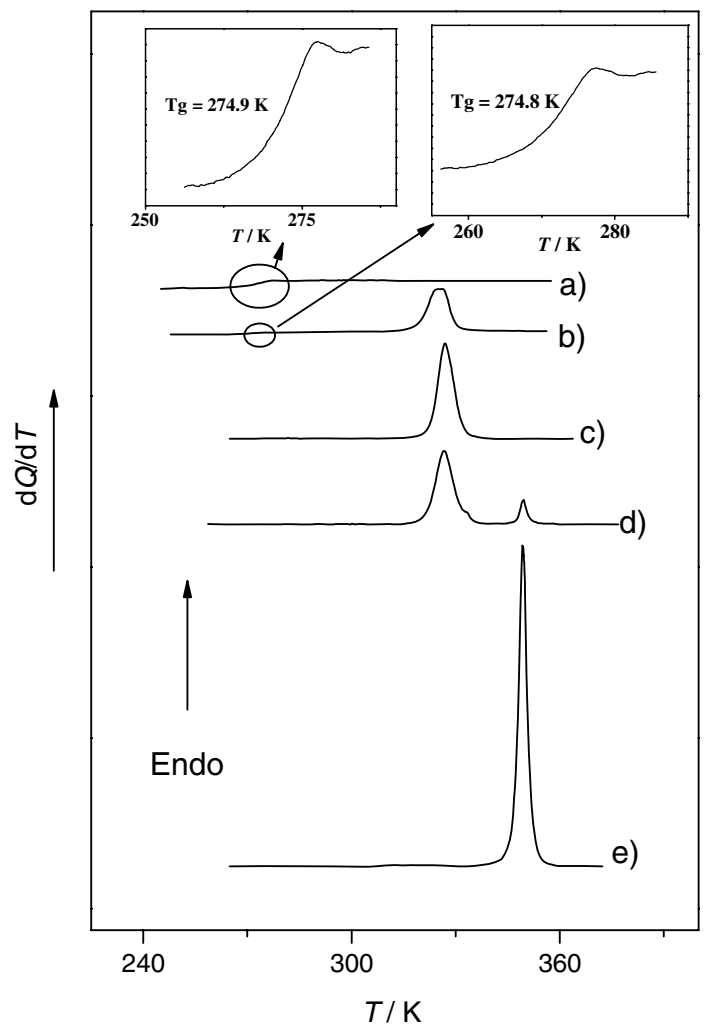

FIGURE 4. $\mathrm{Pb}(\mathrm{C} 4)_{2}$ d.s.c. thermograms, second and following heatings, depending on the wait time: (a) registered immediately, (b) after $10 \mathrm{~h}$, (c) after $18 \mathrm{~h}$, (d) after 1 month, and (e) after 2 months.

At least three different pans of different weight for each compound were studied to obtain the average data of temperature, enthalpy and entropy.

\subsection{1. $\mathrm{Pb}(\mathrm{C2})_{2}$ and $\mathrm{Pb}(\mathrm{C3})_{2}$}

Lead (II) acetate and propanoate have similar thermal behaviour (see figures 1 and 2, respectively): both present only a fusion (1a and $2 \mathrm{a}$, respectively) when heated from the crystalline phase. Both compounds quench into the glass state when being cooled rapidly at about 10 to $20 \mathrm{~K} \cdot \min ^{-1}$ until the temperature of about $250 \mathrm{~K}$ is reached (starting temperature of the thermograms). In a second heating ( $1 \mathrm{~b}$ and $2 \mathrm{~b}$, respectively), a glass transition followed by crystallization and a fusion are observed. The following heating reproduced exactly the second ones as long as the experimental conditions already described are repeated. This behaviour was also observed by optical microscopy: some degrees above its glass transition $\left(T_{\mathrm{g}}\right)$, the glass phase (isotropic to the polarized light) transforms on heating into a crystal phase (birefringent), which finally melted to an isotropic liquid.

It is well known that the glass transition temperature and the temperature of crystallization on heating, taking place some degrees below the regular fusion, depends on the heating rate, due to the kinetic nature of the process.

Thermal functions (transition temperatures, $\Delta_{\text {trs }} H$, $\Delta_{\text {trs }} S$ ) for fusion and crystallization, and the glass transition 
temperature $\left(T_{\mathrm{g}}\right)$ of $\mathrm{Pb}(\mathrm{C} 2)_{2}$ and $\mathrm{Pb}(\mathrm{C} 3)_{2}$ are summarized in table 1.

\subsection{2. $\mathrm{Pb}(\mathrm{C} 4)_{2}$}

Lead (II) butanoate behaves to some extent differently: it presents only a fusion during the first heating (figure 3 ) from the stable crystal phase; but when it is cooled rapidly at about $10 \mathrm{~K} \cdot \mathrm{min}^{-1}$ down to about $T=240 \mathrm{~K}$, the thermal behaviour changes depending on the temperature at which the sample was cooled, and on the elapsed time until it is heated again. Thus, if the thermogram is recorded immediately after cooling (figure 4a), only a glass transition is observed, indicating that at the starting temperature the sample was $100 \%$ in the glass state. On the other hand, waiting about $10 \mathrm{~h}$ at room temperature resulted in the crystallization of a new solid phase (figure $4 \mathrm{~b}$ ), confirmed by the appearance of a $T_{\mathrm{g}}$ at the same temperature (with a smaller value of heat capacity increment) followed by an endothermic peak at $T=322.8 \mathrm{~K}$, associated with a fusion to a new crystal phase. Thermogram $4 \mathrm{c}$ was recorded after waiting $18 \mathrm{~h}$ at room temperature, time sufficient for the total conversion into this new crystalline phase, proved by the absence of the glass transition. This crystalline phase could be a polytype or a monotropic polymorph, and is metastable according to its lower melting point and its slow conversion to the initial phase after waiting for a long time. After 1 month, a partial conversion (metastable crystal to stable crystal) was seen (figure 4d), while after waiting for 2 months total conversion was obtained (figure 4e).

Temperatures, enthalpies, and entropies of the stable phase (figure 3) and of the transitions in thermograms $4 \mathrm{c}$ and $4 \mathrm{e}$, including the $T_{\mathrm{g}}$ for figure $4 \mathrm{a}$, are given in table 2 .

\subsection{X-ray diffraction}

Only two lead (II) $n$-alkanotes have been studied as single crystals by X-ray diffraction: lead (II) acetate trihy- drated [17] and $n$-heptanoate [18] (monoclinic and triclinic structure, respectively), although the former is not comparable with the members studied here since it is a hydrated compound.

The X-ray of $\mathrm{Pb}(\mathrm{C} 7)_{2}$ single crystal shows a triclinic and bilayered structure, with two different alternating layers: one ionic (lead (II) cations and carboxylates) and another lipidic (van der Waals interactions between the $\mathrm{CH}_{3}$ at the end of the chains). All the chains are in all-trans conformation and slightly tilted.

The main structural difference among the different members must be the $c$ parameter, which depends only on the length of the aliphatic chain. Thus, its very easy to infer the $d$-spacing (between layers) of these short lead (II) alkanoates by XRD powder diffraction (001 planes). In figure 5 , the experimental $d$-spacing values of $\mathrm{Pb}(\mathrm{C} 2)_{2}, \mathrm{~Pb}(\mathrm{C} 3)_{2}$, and $\mathrm{Pb}(\mathrm{C} 4)_{2}$ are given, together with the calculated value for the $\mathrm{Pb}(\mathrm{C} 7)_{2}$ from its single crystal data [18]. Except for $\mathrm{Pb}(\mathrm{C} 2)_{2}$, the $d$-spacing for the other members can be fitted to a linear equation, whose slope agrees with the $\mathrm{CH}_{2}$ increment in the trans position in each chain $(\Delta d)$, so $\mathrm{Pb}(\mathrm{C} 3)_{2}$ and $\mathrm{Pb}(\mathrm{C} 4)_{2}$ might be considered iso-structural with $\mathrm{Pb}(\mathrm{C} 7)_{2}$.

The $\mathrm{Pb}(\mathrm{C} 2)_{2} d$-spacing deviates from the correlation found, indicating that its crystalline structure is not comparable. As is well known, the anhydrous compounds have always more symmetry than the hydrated ones; since lead (II) acetate trihydrated is monoclinic, even more symmetry is expected for $\mathrm{Pb}(\mathrm{C} 2)_{2}$, explaining its $d$-spacing deviation.

\subsection{FTIR spectroscopy}

The FTIR spectra of $\mathrm{Pb}(\mathrm{C} 2)_{2}, \mathrm{~Pb}(\mathrm{C} 3)_{2}$, and $\mathrm{Pb}(\mathrm{C} 4)_{2}$ were recorded from room temperature to above their melting points and cooling back to room temperature. The measured $\Delta v$, between the $v_{\text {as }}$ and $v_{\text {sym }}$ carboxylate vibrations in the crystals are about $149 \mathrm{~cm}^{-1}, 139 \mathrm{~cm}^{-1}$, and $113 \mathrm{~cm}^{-1}$, respectively. These values are intermediate

TABLE 1

$\mathrm{Pb}(\mathrm{C} 2)_{2}$ and $\mathrm{Pb}(\mathrm{C} 3)_{2}$ thermal functions, in (a) first, and (b) second and following heatings

\begin{tabular}{lllllllll}
\hline $\mathrm{Pb}(\mathrm{C} n)_{2}$ & & $T_{\mathrm{f}} / \mathrm{K}$ & $\Delta_{\mathrm{f}} H /\left(\mathrm{kJ} \cdot \mathrm{mol}^{-1}\right)$ & $\Delta_{\mathrm{f}} S /\left(\mathrm{J} \cdot \mathrm{K}^{-1} \cdot \mathrm{mol}^{-1}\right)$ & $T_{\mathrm{g}} / \mathrm{K}$ & $T_{\text {crys }} / \mathrm{K}$ & $\Delta_{\text {crys }} H /\left(\mathrm{kJ} \cdot \mathrm{mol}^{-1}\right)$ & $\Delta_{\text {crys }} S /\left(\mathrm{J} \cdot \mathrm{K}^{-1} \cdot \mathrm{mol}^{-1}\right)$ \\
\hline $\mathrm{Pb}(\mathrm{C} 2)_{2}$ & (a) & $452.6 \pm 0.6$ & $16.0 \pm 0.1$ & $35.4 \pm 0.3$ & & & & \\
& (b) & $452.3 \pm 0.8$ & $15.8 \pm 0.1$ & $34.9 \pm 0.3$ & $314.4 \pm 0.5$ & $358.9 \pm 0.7$ & $-11.6 \pm 0.3$ & $-32.3 \pm 0.8$ \\
$\mathrm{~Pb}(\mathrm{C} 3)_{2}$ & (a) & $398.2 \pm 0.4$ & $13.1 \pm 0.1$ & $32.9 \pm 0.3$ & & & & \\
& (b) & $398.1 \pm 0.5$ & $13.1 \pm 0.1$ & $32.9 \pm 0.3$ & $289.0 \pm 0.4$ & $330.6 \pm 0.5$ & $-7.9 \pm 0.3$ & $-23.9 \pm 0.9$ \\
\hline
\end{tabular}

$T_{\mathrm{g}}$ and $T_{\text {crys }}$ were measured at a heating rate of $5 \mathrm{~K} \cdot \mathrm{min}^{-1}$.

TABLE 2

Thermal data for $\mathrm{Pb}(\mathrm{C} 4)_{2}$, in its first heating (figure 3) and following (figure $4 \mathrm{a}, \mathrm{c}$ and e)

\begin{tabular}{llcc}
\hline Thermograms & $T_{\mathrm{f}} / \mathrm{K}$ & $\Delta_{\mathrm{f}} H /\left(\mathrm{kJ} \cdot \mathrm{mol}^{-1}\right)$ & $\Delta_{\mathrm{f}} S /\left(\mathrm{J} \cdot \mathrm{K}^{-1} \cdot \mathrm{mol}^{-1}\right)$ \\
\hline 3 & $346.5 \pm 0.3$ & $14.7 \pm 0.1$ & $42.4 \pm 0.3$ \\
$4 \mathrm{a}$ & & & \\
$4 \mathrm{c}$ & $322.8 \pm 0.5$ & $7.7 \pm 0.4$ & $32 \pm 2$ \\
$4 \mathrm{e}$ & $346.3 \pm 0.4$ & $14.6 \pm 0.1$ & $42.2 \pm 0.3$ \\
\hline
\end{tabular}

$T_{\mathrm{g}}$ was measured at a heating rate of $5 \mathrm{~K} \cdot \mathrm{min}^{-1}$. 


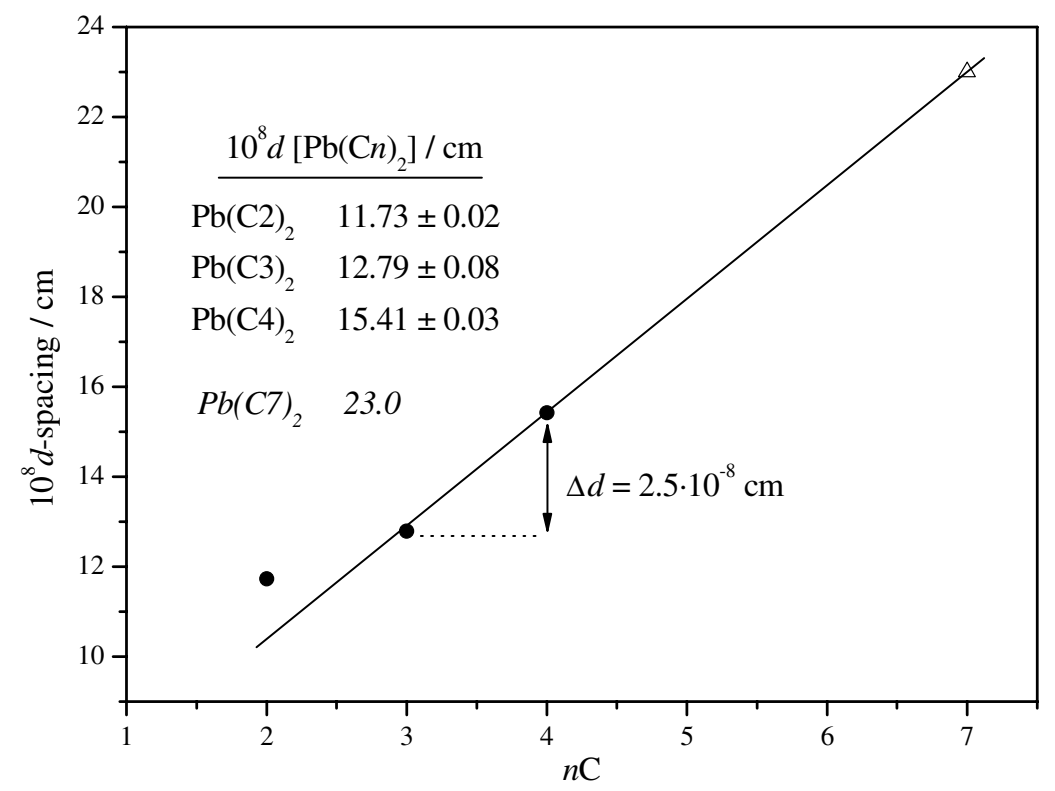

FIGURE 5. Plot of the $d$-spacing against number of carbons, representing the calculated values for $\mathrm{Pb}(\mathrm{C} 2)_{2}, \mathrm{~Pb}(\mathrm{C} 3)_{2}$, and $\mathrm{Pb}(\mathrm{C} 4)_{2}(\bullet)$, and those extracted from the literature for $\mathrm{Pb}(\mathrm{C} 7)_{2}(\triangle)$.

between those corresponding to bridging and chelating bidentate carboxylate coordinations [19], in agreement with the X-ray results obtained for other lead alkanoates single crystals in the literature $[17,18]$ (both structures show two kinds of carboxylates: half of them are "only chelating", and the other half, "bridging-chelating").

The FTIR spectra of $\mathrm{Pb}(\mathrm{C} 2)_{2}$ and $\mathrm{Pb}(\mathrm{C} 3)_{2}$ in the solid and liquid phases are almost identical and no changes are observed on cooling (figure 6a and b). Therefore, infrared spectra do not allow distinguishing the glass from the liquid or solid phases.

On the contrary, the infrared spectrum of $\mathrm{Pb}(\mathrm{C} 4)_{2}$ depends on the sample temperature, and changes (on band frequencies and intensities, and on band splittings) are observed. So, the $\mathrm{CH}_{2}$ scissoring (around $1460 \mathrm{~cm}^{-1}$ ) and rocking (around $750 \mathrm{~cm}^{-1}$ ) bands split in the solid phase spectrum, but only one band is observed in the melted sample. Also, the shift between $v_{\text {as }}$ and $v_{\text {sym }}$ carboxylate vibrations varies from $113 \mathrm{~cm}^{-1}$ in the crystal to $130 \mathrm{~cm}^{-1}$ in the liquid phase. All these features reflect changes in the carboxylate environment and in the chain mobility in the melting transition in concordance with the thermal behaviour already described. It is worth mentioning that, as can be seen in figure 7, the original spectrum is not recovered after cooling back to room temperature coincident with the existence of a metastable solid phase detected by d.s.c..

According to the d.s.c. and FTIR experimental results, $\mathrm{Pb}(\mathrm{C} 4)_{2}$ shows two different structures in solid state (one stable and other metastable), pointing to a kind of monotropic polymorphism or polytypism, frequently present in bilayered compounds (e.g., organic acids [20]). The conversion of one of these two phases into another never could be recorded by d.s.c.. This behaviour is typical of those phenomena. The metastable phase (the one with lower melting point) always appears on cooling the sample from the melt, and could be considered the polytype/polymorph of the stable crystalline phase of $\mathrm{Pb}(\mathrm{C} 4)_{2}$.

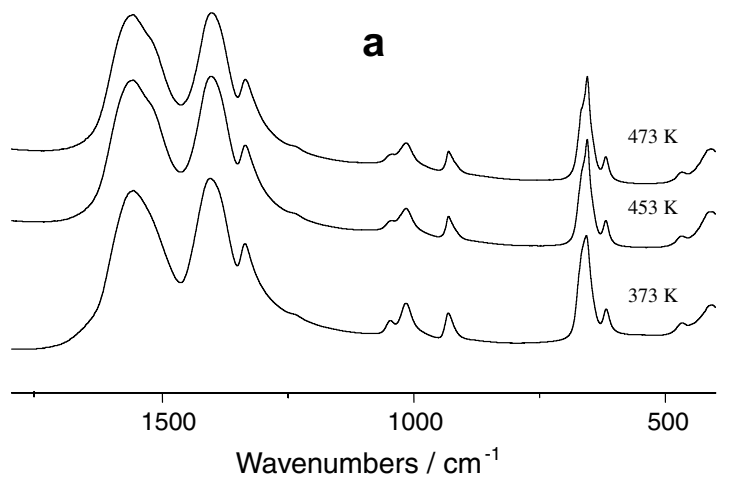

b

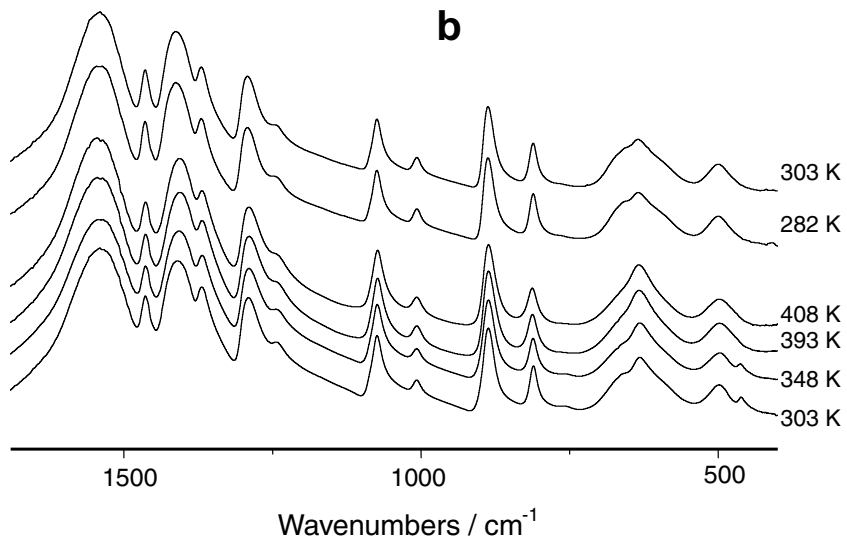

FIGURE 6. FTIR spectra of (a) $\mathrm{Pb}(\mathrm{C} 2)_{2}$ and (b) $\mathrm{Pb}(\mathrm{C} 3)_{2}$ at the specified temperatures. The two upper spectra of $\mathrm{Pb}(\mathrm{C} 3)_{2}$ were recorder on cooling back the sample. 

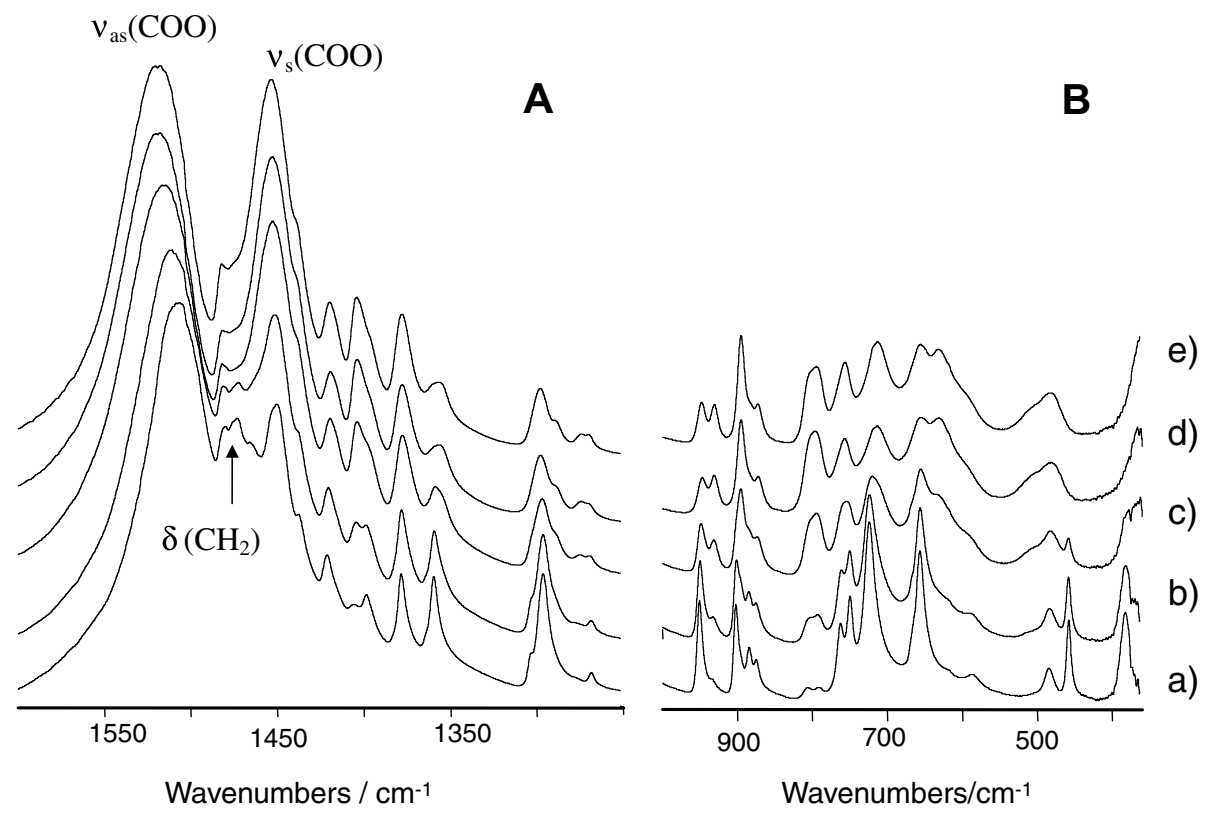

FIGURE 7. FTIR spectra of $\mathrm{Pb}(\mathrm{C} 4)_{2}$ at $T$ : (a) $295 \mathrm{~K}$, (b) $318 \mathrm{~K}$, (c) $333 \mathrm{~K}$, (d) $353 \mathrm{~K}$ on heating and (e) $308 \mathrm{~K}$ on cooling, after melting.

\section{Conclusions}

Thermodynamic data of these three salts almost complete the study of the lead (II) $n$-alkanoates, only the $\mathrm{Pb}(\mathrm{C} 5)_{2}$ remains. The temperatures and enthalpies of the different transitions for the lead (II) $n$-alkanoates series are represented in figures 8 and 9, respectively.

The simpler thermal behaviour of the shortest members with respect to the intermediate and large ones can be clearly seen. The intermediate condis and liquid crystal phases disappear for the compounds studied here. Lead (II) $n$-pentanoate, which shows rather compli-

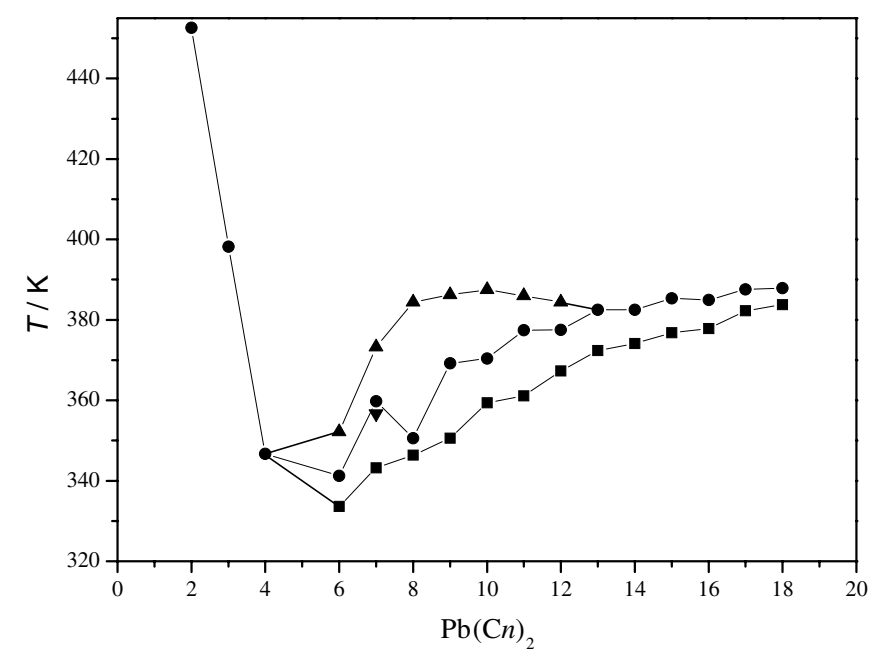

FIGURE 8. Plot of the transition temperatures for the $\mathrm{Pb}(\mathrm{Cn})_{2}$ series, where $(\mathbf{O})$ : melting point, $(\boldsymbol{\Lambda})$ clearing temperatures, $(\boldsymbol{\square})$ solid-to-condis phase, and $(\boldsymbol{\nabla})$ different solid-to-solid transition for the $\mathrm{Pb}(\mathrm{C} 7)_{2}$. cated behaviour under study, must be the link of both groups.

As has been described, $\mathrm{Pb}(\mathrm{C} 2)_{2}, \mathrm{~Pb}(\mathrm{C} 3)_{2}$, and $\mathrm{Pb}(\mathrm{C} 4)_{2}$ are also characterized by their easy formation of glassy states. Thus, kinetic studies should be carried out in order to thoroughly characterize the properties of these amorphous phases.

In the case of the lead (II) butanoate, it is important to note its nature as an ionic liquid. These compounds are organic salts where, normally, the organic chain comes from the cation, such alkylammonium salts; thus, $\mathrm{Pb}(\mathrm{C} 4)_{2}$ can be considered one of the few salts (behaving as ionic liquids) based on an anionic organic chain.

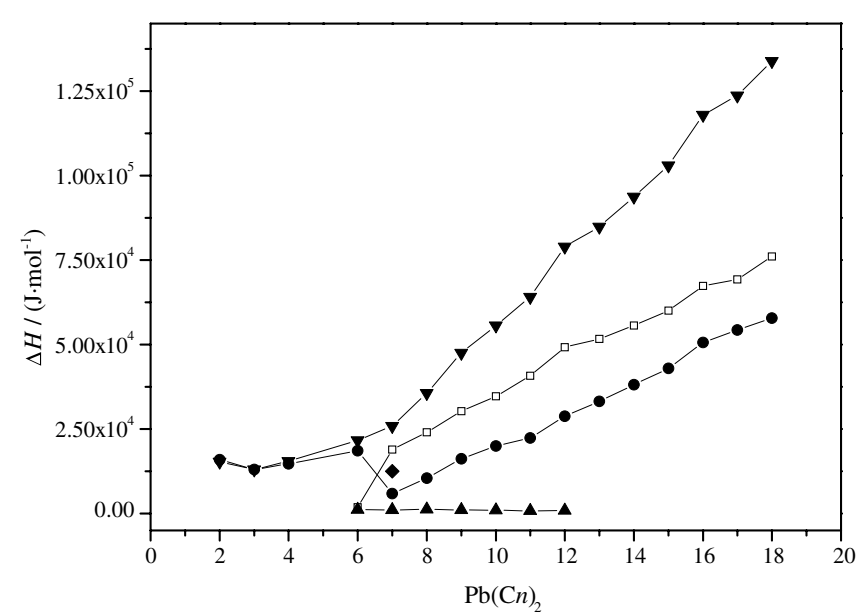

FIGURE 9. Plot of the transition enthalpies for the $\mathrm{Pb}(\mathrm{Cn})_{2}$ series, where (๑) melting point, $(\mathbf{\Lambda})$ clearing temperatures, $(\square)$ solid-to-condis phase, $(\bullet)$ different solid-to-solid transition for the $\mathrm{Pb}(\mathrm{C} 7)_{2}$, and $(\boldsymbol{\nabla})$ total enthalpy. 


\section{Acknowledgement}

Partial support of this research by the DGICYT of the Spanish "Ministerio de Educación y Ciencia" (Grant in aid for Scientific Research is greatfully acknowledged.).

\section{References}

[1] C.G. Bazuin, D. Guillon, A. Skoulios, A.M. Amorim da Costa, H.D. Burrows, C.F.G.C. Geraldes, J.J.C. Teixeira Dias, E. Blackmore, G.J.T. Tiddy, Liq. Cryst. 3 (12) (1988) 1655-1670.

[2] J. Schwede, L. Koehler, H.P. Grossmann, M. Pietralla, H.D. Burrows, Liq. Cryst. 16 (2) (1994) 267-276.

[3] H.A. Ellis, J.W.C. de Vries, Mol. Cryst. Liq. Cryst. 163 (1988) 133 139.

[4] A.M. Amorim da Costa, H.D. Burrows, C.F.C.G. Geraldes, J.J.C. Teixeira Dias, C.G. Bazuin, D. Guillon, A. Skoulios, E. Blackmore, G.J.T. Tiddy, D.L. Turner, Liq. Cryst. 1 (3) (1986) 215-226.

[5] A. Sánchez Arenas, M.V. García, M.I. Redondo, J.A.R. Cheda, M.V. Roux, C. Turrión, Liq. Cryst. 18 (1995) 431-441.

[6] G.W. Smith, in: G.H. Brown (Ed.), Advances in Liquid Crystals, vol. 1, Academic Press, New York, 1975, p. 193.

[7] B. Wunderlich, M. Möler, J. Grebowicz, H. Baur, in: H. Höcker (Ed.), Conformational Motion and Disorder in Low and High Molecular Mass Crystals, Advances in Polymer Science, 87, SpringerVerlag, Heidelberg, 1988.

[8] S.A. Adeosun, S.J. Sime, Thermochim. Acta 27 (1978) 319-327.
[9] M.E. Ekwunife, M.U. Nwachukwu, F.P. Rinehart, S.J. Sime, Chem. Soc. Faraday Trans. I. 71 (1975) 1432-1446.

[10] P. Franzosini, M. Sanesi, Thermodinamic and Transport Properties of Organic Salts, Pergamon Press, London, 1980.

[11] J.E. Martyn, K.R. Seddon, Pure Appl. Chem. 72 (7) (2000) 13911398.

[12] K.R. Seddon, J. Chem. Technol. Biotechnol. 68 (1997) 351-356.

[13] T.A. Mirnaya, S.V. Volkov, in: R.D. Rogers et al. (Eds.), Ionic Liquid Crystals as Universal Matrices (Solvents). Main Criteria for Ionic Mesogenicity. Green Industrial Applications of Ionic Liquids, NATO Science Series, Kluwer Academic Publ., 2003, pp. 439456.

[14] J.A. Duffy, M.D. Ingram, J. Am. Ceram. Soc. 52 (1969) 224-225.

[15] M.D. Ingram, G.G. Lewis, J.A. Duffy, J. Phys. Chem. 76 (7) (1972) $1035-1040$.

[16] R.F. Bartholomew, S.S. Lewek, J. Am. Ceram. Soc. 56 (8) (1970) 445-447.

[17] R.G. Bryant, V.P. Chacko, M.C. Etter, Inorg. Chem. 23 (1984) 3580 3584.

[18] F. Lacouture, M. Francois, C. Didierjean, J.P. Rivera, E. Rocca, J. Steinmetz, Acta Crystallogr. Sect., C: Cryst. Struct. Commun. 57 (2001) 530-531.

[19] K. Nakamoto, P.J. McCarthy, Spectroscopy and Structure of Metal Chelate Compounds, John Wiley, New York, 1968.

[20] K. Sato, W. Kobayashi, in: N. Kare (Ed.), Crystals, Growth, Properties and Applications: Organic crystals, vol. 1, Springer-Verlag, 1991, pp. 65-108.

JCT 06-176 